\title{
Mudanças das políticas culturais no Brasil: da modernidade à pós-modernidade
}

\section{Lucas Belmino Freitas*}

Resumo: 0 objetivo do artigo é analisar as transformações das políticas culturais brasileiras. A primeira e a segunda parte fazem uma diferenciação entre modernidade e pós-modernidade; a terceira parte apresenta as mudanças na política cultural brasileira desde o Estado Novo (1937-45) até os dias atuais. A política cultural do Estado Novo é considerada como sendo moderna, e a política cultural atual é tida como pós-moderna.

Palavras-chave: política cultural, pós-modernidade, financiamento da cultura, sociologia da cultura.

\section{Introdução}

O artigo busca compreender as políticas culturais brasileiras atuais como inscritas dentro do contexto pós-moderno. Para isso, é necessário definir o que vem a ser a pós-modernidade e quais são suas mudanças em relação à modernidade. A primeira parte do artigo trata sobre a modernidade e as práticas culturais nesse período. A segunda parte discute a respeito da pós-modernidade e das práticas culturais nesse contexto. $\mathrm{O}$ objetivo da primeira e da segunda parte é realizar uma diferenciação entre o período moderno e o pós-moderno para analisar as políticas culturas brasileiras. A política cultural no Brasil é considerada, em um primeiro momento, como moderna. A política cultural atual é considerada, pelo artigo, como pós moderna. A terceira e a quarta parte do artigo tratam das questão das políticas culturais. Na terceira parte, isso é feito de uma maneira mais ampla, realizando uma diferenciação entre políticas culturais no mundo. Para isso, o artigo realiza uma breve análise das políticas culturais francesa e estadunidense, que são consideradas tipos ideais extremos de financiamento. A última parte do artigo trata, especificamente, da política cultural brasileira. Nessa parte, é feito um breve histórico, identificando características modernas e pós-modernas das políticas culturais.

\section{Desenvolvimento}

Para compreender o papel do financiamento público da cultura na modernidade é preciso entender primeiro o que vem a ser a experiência moderna. Para uma con-

\footnotetext{
* Graduando em Ciências Sociais - UNB.
} 
cepção inicial, Anthony Giddens (1991) afirma que a modernidade refere-se a estilo, costume de vida ou organização social emergente na Europa a partir do século XVII e que, posteriormente, teve influência mais ou menos global. Giddens vê a modernidade como um conjunto de descontinuidades. Para esse autor, a modernidade se desvencilha de todos os outros tipos tradicionais de ordem social. Giddens considera também que as transformações ocorridas na modernidade são mais profundas do que a maioria dos tipos de mudanças sociais dos períodos anteriores no que se refere a extensionalidade e a intensionalidade.

Para Giddens, essas descontinuidades causadas pela modernidade têm características específicas. Uma característica importante seria o ritmo da mudança: a rapidez nas mudanças é extrema quando comparada aos sistemas pré-modernos. Essa rapidez é perceptível sobretudo na tecnologia, mas também pode ser constatada em todas as outras esferas. Jürgen Habermas, em $O$ discurso filosófico da modernidade, afirma que:

enquanto que no Ocidente cristão os novos tempos designaram o tempo ainda para vir que se abriria ao homem só após o Juízo Final - e é ainda na Filosofia das Idades do Mundo de Schelling - o conceito profano de idade moderna exprime a convicção de que o futuro já começou, significa a época que vive dirigida para o futuro, a qual se abriu ao novo que há de vir (HABERMAS, 1998, p. 17).

Outra descontinuidade apresentada por Giddens é o escopo da mudança: na medida em que distintas regiões geográficas são postas em interconexão, movimentos de transformação sociais se espalham através de toda a superfície da terra. A última descontinuidade proposta por Giddens versa sobre a natureza intrínseca das instituições modernas. Algumas formas sociais modernas, como o surgimento do estado-nação, a transformação de produtos em mercadorias e o trabalho assalariado, não são encontradas em nenhum período anterior.

Ao estudar a modernidade, Giddens procura caracterizar as suas dimensões institucionais e entender as relações entre essas dimensões. As dimensões institucionais são: o capitalismo, o industrialismo, o poder militar e a vigilância. 0 capitalismo, para Giddens, é um sistema de produção de mercadorias centrado na propriedade privada do capital e no trabalho assalariado sem posse de propriedade. A principal característica do industrialismo é a utilização de fontes inanimadas de energia material na produção de bens. 0 industrialismo pressupõe a organização social regularizada da produção com o intuito de coordenar a atividade humana, as máquinas e os usos de matéria-prima e bens. Outra dimensão institucional é o 
o controle do poder militar. O monopólio dos meios de violência dentro de fronteiras territoriais é característica específica do Estado moderno. Max Weber define o Estado moderno da seguinte maneira:

o Estado moderno é um agrupamento de dominação que apresenta caráter institucional e que procurou - com êxito - monopolizar, nos limites de um território, a violência física legítima como instrumento de domínio e que, tendo esse objetivo, reuniu nas mãos dos dirigentes os meios de gestão (WEBER, 2003, p. 66).

A última dimensão institucional caracterizada por Giddens é a vigilância, que se refere à supervisão das atividades da população súdita na esfera política. Essa vigilância pode ocorrer de forma indireta ou direta.

A partir dessa caracterização introdutória da concepção de modernidade, é preciso entender como era o papel do produtor cultural dentro do contexto moderno. Zygmunt Bauman (2010), no livro Legisladores e intérpretes, analisa o conceito de intelectual. Para Bauman, o termo "intelectual" é de origem histórica recente e refere-se a um grupo de pessoas com uma ocupação e uma posição social diferenciada. 0 termo surge como uma tentativa de agregar pessoas que exercem diferentes atividades profissionais, como cientistas, escritores, artistas, entre outros. Essa agregação traz um papel a esse grupo, o papel de dirigir a nação, que se legitima através da razão e da autoridade moral que esse grupo possui. Uma característica dos tempos modernos é a explicitação plural de discursos em comparação com a unilateralidade da religião na produção discursiva. Os intelectuais ganham espaço, uma vez que foi vinculado aos seus discursos a veracidade, baseada na razão e na autoridade moral.

No período moderno, o trabalho do intelectual é caracterizado por Bauman pela metáfora do legislador. Para ele, o papel do intelectual moderno "consiste em fazer afirmações autorizadas e autoritárias que arbitrem controvérsias de opiniões e escolham aquelas que, uma vez selecionadas, se tornem corretas e associativas" (BAUMAN, 2010, p. 20). 0 poder do intelectual de arbitrar é legitimado por meio de bases acadêmicas e científicas, pois há uma crença de que com os métodos adotados por essas autoridades é possível alcançar a verdade, um juízo moral ou um gosto artístico adequado.

Michel Foucault (2009) defende que em toda sociedade a produção do discurso é controlada, organizada, selecionada e redistribuída por um certo número de procedimentos. Toda produção de discursos, para Foucault, tem uma ligação com o desejo e o poder, porém o discurso não é só aquilo que manifesta o desejo, mas aquilo pelo o que se luta. Pierre Bourdieu, em Coisas ditas, discute a respeito da luta pelas palavras: 
o mundo social é um lugar de lutas a propósito de palavras que devem sua gravidade - e às vezes sua violência - ao fato de que as palavras fazem as coisas, em grande parte, e ao fato de que mudar as palavras e, em termos gerais, as representações já é mudar as coisas (BouRdiEu, 1990, p. 71).

A busca de legitimação dos modernos se dá em uma batalha com os antigos. Joan Dejean, em Antigos contra modernos, aborda a chamada guerra cultural, ocorrida no campo literário francês do século XVII, em que os antigos e os modernos travaram uma batalha sobre qual seria a literatura digna de ser considerada grandiosa e qual seria a mais adequada para preencher os currículos literários estudantis:

a primeira lição do conflito do século XVII entre Antigos e Modernos foi a de que qualquer proclamação de modernidade automaticamente força àqueles que discordem dela a definirem-se a si próprios em desafio como Antigos, provocando, desta forma, o ciclo das Guerras Culturais, isto é, as lutas pela determinação de quem são os autores clássicos e pela autoridade e direito de expressão destes autores (DEJEAN, 2005, p. 44).

Pierre Bourdieu (2005) afirma que a história da vida intelectual e artística das sociedades europeias revela-se através da história das transformações da função do sistema de produção de bens simbólicos e da própria estrutura desses bens. Ocorre uma automatização progressiva do sistema de relações de produção, circulação e consumo de bens culturais. Bourdieu afirma que durante toda a Idade Média e parte do Renascimento a vida intelectual e artística estava sob tutela da Igreja e da aristocracia, porém foi se libertando progressivamente desse controle e se afastando também de suas demandas éticas e estéticas. Com essa libertação, ocorre a constituição de um campo artístico e intelectual, que se define em oposição a outros campos. A partir daí, o poder de legislar na esfera cultural passa a ser restrito àqueles que possuem poder e autoridade propriamente culturais.

O processo de automatização do campo intelectual e artístico se sucedeu, segundo Bourdieu, conjuntamente com uma série de outras transformações: 1) a constituição de um público de consumidores cada vez mais extenso e diversificado, que possibilitava aos produtores de bens simbólicos uma independência econômica e uma legitimação paralela, 2) o surgimento de um grupo cada vez mais numeroso de produtores e empresários de bens simbólicos, 3) o aumento do número e da diversidade de instâncias de consagração competindo pela legitimidade cultural.

Bourdieu afirma que o processo de automatização da produção intelectual e artística está relacionado à formação de um grupo mais inclinado a levar em conta as regras afirmadas pela própria esfera intelectual ou artística. Esse processo tem 
ligação tanto com a mudança na relação entre artistas e não-artistas quanto com a alteração nas relações entre os próprios artistas, o que resulta em uma nova definição da função da arte e da função do artista. Esse movimento de automatização, segundo Bourdieu, ocorreu em ritmos diferentes entre as sociedades europeias, porém em todas elas esse processo se acelera sensivelmente com a Revolução Industrial. A partir do momento em que um mercado de obra de arte é constituído, os escritores e artistas têm a possibilidade de afirmar em suas representações e práticas a singularidade de sua condição artística e a irredutibilidade da obra de arte ao estatuto de simples mercadoria. Instaura-se assim uma dissociação entre a arte como simples mercadoria e a arte como pura significação.

Walter Benjamin, em "A obra de arte na era da sua reprodutibilidade técnica", questiona a respeito da autenticidade da obra de arte. Para ele, há uma diferença entre a obra de arte e sua reprodução. Mesmo quando as reproduções deixam intacto o conteúdo da obra, há um abalo na autenticidade do objeto. Para Benjamin, a autenticidade de uma obra é transmitida pela tradição, a partir de sua origem e é dependente de sua materialidade. 0 conceito de aura de Benjamin resume as características da autenticidade:

O conceito de aura permite resumir essas características: o que se atrofia na era da reprodutibilidade técnica da obra de arte é a sua aura. Esse processo é sintomático, e sua significação vai muito além da esfera da arte. Generalizando, podemos dizer que a técnica da reprodução destaca do domínio da tradição o objeto reproduzido (BENJAMIN, 1985, p. 168).

Benjamin diz que a reprodução da arte permite multiplicar a existência única da obra, o que amplia o acesso dos espectadores às reproduções e permite atualizar constantemente o objeto reproduzido. Isso representa um violento abalo à tradição.

Após analisar como se davam as práticas culturais na modernidade, é importante perceber as mudanças ocorridas nessas práticas na pós-modernidade. É necessário, para isso, definir o que é pós-modernidade, como ela surge, quais as suas diferenças em relação a modernidade e como ficam as práticas culturais nesse novo contexto.

A vanguarda artística pós-moderna estendeu sua influência em diversos meios artísticos. Um campo importante para o surgimento da vanguarda artística pós-moderna foi a arquitetura. Segundo datação simbólica realizada pelo teórico da arquitetura Charles Jencks, a passagem do modernismo para o pós-modernismo na arquitetura ocorreu em 1972. Esse foi o ano em que o projeto de desenvolvimento da 
habitação Pruitt-Igoe, de St. Louis, foi demolido por ser considerado um ambiente inabitável. Para Charles Jencks, essa demolição foi o símbolo da morte do modernismo. Nesse mesmo ano, ocorreu a publicação de Learning from Las Vegas, livro escrito pelos arquitetos Robert Venturi e Denise Scott-Brown. Nele, os autores insistiam que os arquitetos aprendessem com o estudo de ambientes populares e comerciais ao invés de buscarem ideais abstratos e teóricos. Para os autores, a arquitetura devia se voltar para as pessoas e não para um homem abstrato.

\begin{abstract}
no campo da arquitetura e do projeto urbano, considero o pós-modernismo no sentido amplo como uma ruptura com a ideia modernista de que o planejamento e o desenvolvimento devem concentrar-se em planos urbanos de larga escala, de alcance metropolitano, tecnologicamente racionais e eficientes, sustentados por uma arquitetura absolutamente despojada (as superfícies "funcionalistas" austeras do modernismo de "estilo internacional"). 0 pós modernismo cultiva, em vez disso, um conceito do tecido urbano como algo necessariamente fragmentado, um "palimpsesto" de formas passadas superpostas umas às outras e uma "colagem" de usos correntes, muitos dos quais podem ser efêmeros (HARVEY, 1993, p. 69).
\end{abstract}

Partindo da arquitetura, a vanguarda pós-modernista influenciou outros campos artísticos, como, por exemplo, a literatura. Linda Hutcheon (1991) vê o pós-modernismo como uma atividade cultural presente na maioria das formas de arte e em muitas correntes de pensamento atuais. Para a autora, o pós-modernismo é fundamentalmente contraditório, histórico e inevitavelmente político. 0 romance pós-modernista, segundo Hutcheon, questiona uma série de conceitos ligados ao chamado humanismo liberal, como a autonomia, a certeza, a autoridade, a universalização e a continuidade.

Fredric Jameson (1997) percebe o pós-modernismo não como um estilo, mas como um dominante cultural. Para Jameson, o pós-moderno é um campo de forças em que vários tipos distintos de impulso cultural têm que encontrar seu caminho. Jameson enumera os elementos constitutivos do pós-moderno, sendo o primeiro deles uma nova falta de profundidade ou um novo tipo de achatamento. Jameson percebe, ao analisar o quadro "Um par de botas”, de Vicent Van Gogh, que é possível considerar o quadro como uma indicação ou um sintoma de uma realidade mais vasta. Observando a obra "Diamond dust shoes", de Andy Warhol, Jameson entende que não é possível reintegrar a obra ao seu contexto vivido. Para ele, nada nesse quadro prevê um espaço. De acordo com Jameson, essa diferença entre os quadros se dá por uma nova falta de profundidade.

ainda que essa espécie de morte do mundo da aparência seja tematizada em alguns trabalhos de Warhol, mais notadamente nas séries de acidentes de trânsito ou de cadeiras 
elétricas, penso que não se trata mais de uma questão de conteúdo, mas de uma mutação mais fundamental, tanto no próprio mundo dos objetos - agora transformados em um conjunto de textos ou de simulacros - quanto na disposição do sujeito (JAMESoN, 1997, p. 37).

De acordo com Jameson, o segundo elemento do pós modernismo é o enfraquecimento da historicidade, tanto em nossas relações com a história pública, quanto nas novas formas de temporalidade privada. Segundo Jameson, com a pós modernidade há uma crescente inviabilidade de um estilo pessoal. Ele aponta que essa inviabilidade de um estilo pessoal motiva a prática do "pastiche", que viria, gradativamente, tomando o lugar da paródia. 0 "pastiche", assim como a paródia, consiste na imitação de um estilo único. Jameson afirma que, diferente da paródia, o "pastiche" é uma prática neutralizada de imitação. De acordo com Jameson, os produtores culturais não podem mais se voltar a nenhum outro lugar que não seja o passado.

Segundo Hutcheon, o pós-modernismo afirma que o acesso ao passado está totalmente condicionado pela textualidade. 0 pós-modernismo não nega que o passado existiu, mas afirma que só é possível conhecê-lo através de seus textos, de seus documentos, de evidências e de relatos.

Jameson afirma que a abordagem do presente se dá através de uma linguagem artística do simulacro ou do "pastiche", abordando, assim, um passado estereotipado. Essa abordagem do presente surge como um sintoma do esmaecimento da historicidade, da chance de experimentar a história ativamente. Jameson diz que essa abordagem do presente na pós-modernidade não é capaz de produzir um ocultamento do presente, mas gera uma situação de incapacidade de produzir representações de nossa própria experiência corrente.

Segundo Jameson, o terceiro elemento do pós-modernismo é a relação da nova falta de profundidade e do esmaecimento da historicidade com a nova tecnologia, que é uma das figuras de um novo sistema econômico mundial. Jameson afirma que é possível se referir ao nosso próprio período como sendo a Terceira Idade da Máquina. Ele afirma que a representação acerca da máquina é distinta em cada estágio de desenvolvimento tecnológico. Jameson diz que no estágio do capital anterior ao atual, ou seja, durante o capitalismo de mercado, havia uma excitação do futurismo e uma grande celebração da metralhadora e do automóvel. A máquina exercia um imenso fascínio.

Jameson afirma que a tecnologia atual não é capaz de gerar esse tipo de representação, pois ela já não é mais representada pelas turbinas ou pelas chaminés de fábricas, mas sim pelo computador e pela televisão. Para Jameson, as máquinas como o 
computador e a televisão são melhor definidas como máquinas de reprodução do que como máquinas de produção. Essas máquinas de reprodução exigem representações estéticas bem distintas das máquinas mais antigas. Jameson foge, assim, da noção pós-marxista de que a tecnologia seria de algum modo determinista da vida social cotidiana e da produção cultural.

Mike Featherstone (1995) sugere que entre as características associadas ao pós-modernismo está uma atitude antifundacional na filosofia e nas teorias social e cultural. Essa atitude antifundacional sugere uma oposição às metanarrativas fundacionais, que assentam as pretensões de uma universalidade privilegiada da modernidade ocidental. Desse modo, na pós-modernidade há uma busca pela construção de um conhecimento com menos pretensões universais e mais atencioso às diferenças locais.

Bauman (2010) realiza uma diferenciação entre a prática intelectual moderna e a pós-moderna. Para ele, a distinção entre modernidade e pós-modernidade é uma distinção entre períodos da história intelectual. Na prática intelectual moderna, o intelectual age como um legislador na medida em que tem o dever e a legitimidade de arbitrar para chegar a um juízo moral ou a um gosto artístico apropriado. No contexto pós-moderno, o intelectual atua como uma espécie de intérprete. Segundo Bauman, o seu papel "consiste em traduzir afirmações feitas no interior de uma tradição baseada em termos comunais, a fim de que sejam compreendidas no interior de um sistema fundamentado em outra tradição" (BAUMAN, 2010, p. 20). Diferente do intelectual moderno, que tinha como prática o aperfeiçoamento da ordem social, o intelectual pós-moderno está mais preocupado em impedir distorções no processo de comunicação entre tradições diferentes. $O$ intelectual visa facilitar o equilíbrio nas interações entre as tradições, impedindo distorções de significados. A prática pós-moderna abandona as pretensões universalistas modernas. A estratégia pós-moderna não implica em uma eliminação da prática moderna, pois é mantida a autoridade baseada na especificidade profissional. 0 intelectual continua legislando, não em busca de um aperfeiçoamento da ordem social, mas sim sobre as regras de procedimentos para se lidar com controvérsias de opinião e com a interação entre tradições distintas.

Featherstone (1995) afirma que na pós-modernidade a produção de conhecimento tem, em geral, menor pretensão universal. A produção de conhecimento no contexto pós-moderno privilegia o local. Esse privilégio do local se traduz em uma derrubada das hierarquias simbólicas nas esferas acadêmicas, intelectuais e artísticas, em que são contestadas as distinções entre a alta cultura e as culturas populares. 
Pierre Bourdieu (2005) realiza uma diferenciação entre o campo de produção erudita e o campo de produção da indústria cultural. Bourdieu entende o campo de produção erudita como um sistema que produz bens culturais para um público que também produz bens culturais. A produção da indústria cultural é voltada para um público não produtor de bens culturais, "o grande público". O campo de produção da indústria cultural é regido pela lei da concorrência e busca conquistar o maior mercado possível. 0 campo da produção erudita, por sua vez, tende a produzir suas próprias normas de produção e avaliação. Este campo obedece a lei da concorrência pela reconhecimento propriamente cultural.

Ronald Inglehart (2005) afirma que as visões clássicas de modernização, como a de Weber e a de Marx, sugeriam que o desenvolvimento econômico gera grandes mudanças sociais, culturais e políticas.

Inglehart, através de dados de pesquisa coletados em 81 sociedades que detêm 85\% da população mundial entre 1981 e 2002, afirma que os valores e crenças básicos das pessoas em sociedades mais avançadas economicamente diferem consideravelmente dos valores e crenças encontrados em sociedades menos desenvolvidas economicamente e socialmente. Inglehart atenta para o fato de que essa mudança sociocultural não é linear. Para ele, os valores emergentes de autoexpressão transformam a modernização em um processo de desenvolvimento humano, produzindo um novo tipo de sociedade, que enfatiza a emancipação humana. Para Inglehart, a primeira fase da modernização mobilizou as massas, o que tornou possível a democracia, o fascismo e o comunismo. Para ele, a democracia é a forma de governo que proporciona possibilidades mais amplas para os indivíduos escolherem como viver suas vidas. A fase pós-industrial da modernização produz demandas de massa progressivamente mais fortes.

Inglehart diz que o desenvolvimento econômico traz níveis cada vez maiores de educação e informação. Ao aumentarem seus recursos econômicos, cognitivos e sociais, as pessoas tornam-se mais independentes, material, intelectual e socialmente. Para Inglehart, "a ênfase cultural passa da disciplina coletiva para a liberdade individual, da conformidade para a diversidade humana e da autoridade do estado para a autonomia individual" (INGLEHART, 2005, p. 19).

Segundo Inglehart, nas sociedades pós-industriais, as pessoas exigem, cada vez mais, a faculdade de escolhas mais livres em todos os aspectos da vida, como a escolha da orientação sexual e dos padrões de consumo, entre outros aspectos. 
Na era pós-industrial, desenvolvimento econômico, valores de autoexpressão em ascensão e democracia efetiva trabalham em conjunto, propiciando meios, valores e direitos que dão às pessoas cada vez mais capacidade, vontade e direito de moldar sua vida segundo suas escolhas autônomas - relativamente livres de restrições externas (INGLEHART, 2004, p. 73).

Zygmunt Bauman (1998) afirma que os mal-estares da pós-modernidade são causados pela liberdade de procura do prazer que tolera uma segurança individual muito pequena. Para Bauman, o mal-estar da pós-modernidade é, nesse sentido, muito diferente do mal-estar da modernidade. Este tinha origem em uma espécie de segurança que tolerava uma liberdade muito pequena na busca do prazer individual.

Para Inglehart, a ênfase progressiva nos valores de autoexpressão não acaba com os desejos materiais, entretanto as orientações econômicas predominantes estão sendo remoldadas. Para ele, o consumo é cada vez menos determinado pela necessidade prática e pela necessidade de sustento. Os valores dos objetos são cada vez mais determinados por um interesse por uma experiência ou por uma distinção através da simbolização de um estilo de vida.

Para Featherstone, a expressão "estilo de vida", dentro do âmbito da cultura de consumo contemporânea, diz respeito à individualidade, à autoexpressão e a uma consciência de si estilizada. Segundo Featherstone, o corpo, as roupas, o lazer e a preferência por determinados alimentos funcionam como indicadores da individualidade do gosto e do senso de estilo do proprietário/consumidor. Featherstone afirma que ao utilizar a expressão "cultura de consumo", está se enfatizando que o mundo das mercadorias e o seus princípios de estruturação são centrais para a compreensão da sociedade contemporânea, o que envolve dois focos:

em primeiro lugar, na dimensão cultural da economia, a simbolização e o uso de bens materiais como comunicadores, não apenas como utilidades; em segundo lugar, na economia dos bens culturais, os princípios de mercado - oferta, demanda, acumulação de capital, competição e monopolização - que operam dentro da esfera dos estilos de vida, bens culturais e mercadorias (FEATHERSTONE, 1995, p. 121).

Para Featherstone, a estetização da realidade coloca em primeiro plano a importância do estilo. Essa atenção ao estilo de vida sugere que as práticas de consumo, a compra, a exibição dos bens e as experiências de consumo na vida cotidiana, não podem ser compreendidos simplesmente mediante o cálculo racional baseado na concepção de valor de troca. Featherstone acrescenta que a própria organização do 
espaço, o planejamento das edificações, é em si mesma uma manifestação de códigos culturais específicos.

Featherstone sugere que alguns grupos sociais, principalmente jovens, assumem uma postura mais ativa em relação ao estilo de vida e se dedicam à estilização da vida. Featherstone exemplifica essa estilização da vida a partir dos "artistas da vida": "os pintores que não pintam, mas adotam as sensibilidades artísticas para transformar suas vidas numa obra de arte" (FeAtherstone, 1995, p. 137). Para Featherstone, essa preocupação com a estilização da vida é o inverso das imagens estereotipadas das sociedades de massa.

As alterações na esfera da economia ocorridas no último quartel do século XX geraram diversas mudanças: na organização do trabalho, nas formas de consumo, entre outras. Houve, historicamente, uma inserção da lógica econômica dentro da esfera cultural. Porém, ocorreu também o movimento inverso, de culturalização da economia. Neste sentindo, diversas partes do processo de consumo estão ligados a uma busca por experiência e por uma estilização da vida. Já não é mais possível entender as trocas econômicas somente através das concepções de valor de troca e valor de uso. A economia não foi um único fator causal nesse processo de mudança social. Os valores e crenças se alteraram devido ao desenvolvimento social e econômico dos países. As pessoas estão exigindo maior liberdade de autoexpressão. Para Inglehart, essa busca por autoexpressão está ligada a uma elevação dos níveis educacionais. Partindo das características apresentadas sobre o pós-modernismo, procuro entender a relação do Estado e o financiamento público da cultura nesse contexto pós-moderno.

É possível observar que, historicamente, houve uma aproximação entre a esfera da produção cultural e a esfera econômica. Isaura Botelho (2001), afirma que mesmo nos países onde o investimento privado na produção cultural prevalece sobre o investimento estatal, como é o caso dos Estados Unidos, o Estado não deixa de assumir um papel de destaque através do financiamento direito das atividades culturais ou buscando corrigir desigualdades econômicas e sociais:

Em outras palavras, para que um sistema efetivo de financiamento às atividades culturais funcione é obrigatório que se estabeleça uma política pública, em que parcerias - tanto entre áreas de governo, num plano horizontal, quanto entre as três instâncias administrativas, num plano vertical - São fundamentais para conquistar novas fontes privadas de financiamento. Consequentemente, para que os incentivos fiscais funcionem é necessário que haja um clima de recepção favorável a eles na sociedade e, nesse sentido, a postura do governo com relação à cultura e às artes é fundamental (BOTELHO, 2001, p. 9). 
A participação do Estado no financiamento das produções culturais tem características distintas entre os países: há aqueles onde a participação do Estado é mais intensa e outros países onde a participação do Estado é menor. Os Estados Unidos são um exemplo de país em que a participação do Estado no financiamento da produção cultural é proporcionalmente bem menor do que aquele proporcionado pelo setor privado. A principal forma de participação do Estado nas atividades culturais se dá através de duas agências: National Endowment for the Arts (NEA) e a National Endowment for the Humanities (NEH). Segundo dados do censo do governo dos Estados Unidos, essas duas agências tiveram a sua disposição em 2009 a soma de 186,8 e 134,5 milhões de dólares, respectivamente. Essas quantias são superadas facilmente pela quantia arrecada em contribuições na filantropia privada. Em 2010, a contribuição arrecada para o setor de artes, cultura e humanidade, segundo a Fundação Giving USA, foi de 13,28 bilhões de dólares.

A principal fonte das contribuições filantrópicas vem dos contribuintes individuais, que em 2010 responderam a 73\% da quantia doada. Miceli afirma que foi instituída nos EUA em 1913 a legislação federal do imposto sobre a renda, que isentou a maioria das organizações filantrópicas dessa modalidade de imposto. Isso mostra que a questão tributária é um fator que influencia a prática filantrópica.

Outra valiosa fonte de recursos para as artes deriva da isenção de diversos tributos (federais, estaduais, locais) e taxas (aquelas incidentes sobre a transmissão de heranças, etc.) concedida às contribuições, doações e legados feitos às organizações sem fins lucrativos. Desde o inicio do século, tal sistema de arrecadação vigente nos EUA tem possibilitado uma expansão duradoura das contribuições filantrópicas às artes (MICELI, 1985b, p. 70).

É possível perceber, no caso dos Estados Unidos, que mesmo não havendo proporcionalmente muita participação direta do Estado no financiamento da produção cultural, ele exerce um papel importante ao incentivar a participação privada no financiamento das práticas culturais.

Miceli identifica a França e Os Estados Unidos como sendo tipos ideais extremos no que diz respeito à política cultural:

A França e os Estados Unidos constituem, por assim dizer, os tipos ideais extremos de uma perspectiva comparada, ou seja, o contraste entre uma política cultural marcada sobretudo pelo vulto da presença governamental e um apoio institucional que depende muito mais das orientações e decisões de contribuintes privados (fundações, corporações ou particulares) do que de recursos públicos (MicELI, 1985a, p. 11). 
As práticas culturais na Europa remontam a grandes períodos em que a atividade cultural era financiada pela aristocracia, pela corte e pelos altos eclesiásticos. Muitas das instituições culturais de grande prestígio na Europa, como as Óperas de Paris e Viena, o Museu do Louvre e o teatro La Scala de Milão, foram consolidadas entre os séculos XVIII e XIX. Miceli afirma que o processo de unificação tardio de alguns países europeus, o aumento da intensidade dos processos de industrialização e urbanização na Europa, a queda de diversas monarquias e outras mudanças políticas importantes ocorridas nos países europeus não afetaram significativamente a continuidade da operacionalização dessas instituições culturais. Após o fim das duas grandes guerras, a maior parte dessas instituições financiadas pela realeza passou para a administração dos Estados, que assumiram a função de financiadores diretos de alguns tipos de artes e artistas. Esse novo papel dos Estados também provém do fato de algumas manifestações artísticas consideradas eruditas não conseguirem, por si só, renda suficiente para se manterem.

O grau de centralização das políticas públicas no campo das artes varia entre os países. Miceli afirma que o grau de centralização das políticas culturais está ligado ao grau de unificação linguística, religiosa e cultural de uma sociedade. Países como a Bélgica e a Suíça, que possuem mais de uma língua nacional, e países como a Holanda, marcada por diferenças religiosas, possuem uma grande repartição dos gastos governamentais com as atividades culturais entre o governo federal, estadual e municipal. A França, por outro lado, é marcada por uma política cultural fortemente centralizada, com pouca participação dos governos estaduais e municipais.

Miceli disserta a respeito da política cultural francesa afirmando que essa esfera tem grande importância política. 0 orçamento do ministério da cultura francês em 1970 correspondia a 5\% do orçamento nacional total. Além disso, quase todos os setores da administração pública reservam uma parcela de seus recursos para o financiamento de alguma atividade cultural. 0 governo Francês é responsável pela manutenção de diversas instituições tidas como essenciais para a definição oficial da cultural nacional. A maioria dessas instituições culturais financiadas pelo governo estão situadas em Paris.

As políticas públicas culturais francesas não se resumem ao financiamento direto e ao repasse de recursos. Também existem fundos de apoio a atividades culturais consideradas importantes para a preservação do prestígio nacional. A política cultural francesa é marcada por uma forte presença do Estado no financiamento das práticas culturais, que é centralizada pelo governo federal francês. 
As políticas culturais brasileiras surgem para a realização de um direito assegurado a partir da constituição de 1988, a condição de direito cultural. Marilena Chauí (1995) afirma que há quatro principais modalidades de relação entre Estado e cultura no Brasil. Para Chauí, a primeira modalidade de relação é a liberal, que identifica cultura e belas-artes (as belas-artes, nesse contexto, são vistas como objeto de consumo de uma elite escolarizada). A segunda forma de relação é a do Estado autoritário, que se apresenta como produtor oficial da cultura e controlador da produção cultural da sociedade. A terceira forma de relação é a populista, em que há uma manipulação da concepção de cultura popular, identificando-a como a produção cultural do povo. A última relação identificada por Chauí é a neoliberal, que identifica cultura e eventos de massa e que tende a privatizar instituições públicas de cultura. Chauí apresenta críticas a todas essas formas de relação entre o Estado e a cultura.

Segundo Chauí, a política cultural deve ser voltada para o usufruto da cidadania cultural. Para ela, a cidadania cultural será implantada através da realização dos seguintes direitos: o direito de acesso e fruição dos bens culturais, o direito à criação cultural, o direito de reconhecer-se como sujeito cultural e o direito à participação nas decisões públicas sobre a cultura. A realização dos direitos culturais é uma das metas das políticas culturais. É possível perceber, na lei № 8.313, de 23 de Dezembro de 1991, que trata da criação do programa nacional de apoio à cultura (PRONAC), a questão dos direitos culturais. 0 artigo $1^{\circ}$ dessa lei define os objetivos do programa: "Art. $1^{\circ}$ Fica instituído o Programa Nacional de Apoio à Cultura (PRONAC), com a finalidade de captar e canalizar recursos para o setor de modo a: I - contribuir para facilitar, a todos, os meios para o livre acesso às fontes da cultura e o pleno exercício dos direitos culturais".

Foram criadas anteriormente à Constituição de 1988 diversas instituições culturais, como o Instituto do Patrimônio Histórico e Artístico Nacional (IPHAN) e o Museu Imperial, criados em 1937 e 1940, respectivamente. A partir do Estado Novo começa a crescer a participação do Estado na esfera cultural. Mônica Pimenta Velloso (1987) afirma que ocorreu, durante o Estado Novo (1937-45), uma aproximação entre as elites intelectuais e o governo. A autora afirma que os intelectuais tinham uma grande preocupação com a construção do nacionalismo. Durante o Estado Novo, as elites intelectuais identificaram o Estado como sendo o cerne da nacionalidade brasileira. Mônica Velloso enfoca que as elites intelectuais, nesse período, estavam profundamente inseridas na organização política e ideológica do regime. Velloso identifica dois 
modos de atuação dentro do projeto educativo proposto pelo Estado: o do Ministério da Educação e o do Departamento de Imprensa e Propaganda. Segundo Velloso, o Ministério da Educação, preocupado com a educação formal, voltava-se para a formação de uma cultura mais erudita. Ele buscava orientar as manifestações da cultura popular, através do controle das comunicações.

Segundo Velloso, no início do século XX, no Brasil, os intelectuais se situavam em uma posição de marginalidade em relação ao Estado. 0 regime do Estado Novo criticava fortemente o ideal esteticista da literatura, o intelectual erudito e o academicismo. Para o regime, os intelectuais possuíam uma função social. Para a autora, ao intelectual é designada a missão de ser o representante da consciência nacional. 0 estado passa a ser um "pai" dos intelectuais e os intelectuais passam a ser colaboradores, possuidores de um dever com a nação. Mônica Velloso afirma que os intelectuais do Estado Novo eram considerados porta-vozes dos desejos da população, eles seriam capazes de captar o "subconsciente" coletivo da nacionalidade.

Émile Durkheim (1983) afirma que a noção de grupo político está na oposição entre governantes e governados, entre a autoridade e os que estão sujeitos a ela. 0 Estado, para Durkheim, é um grupo de funcionários que constroem vontades e representações que envolvem a coletividade. 0 Estado é, nesse sentido, o órgão do pensamento social e, ao pensar, ele dirige a consciência coletiva. Para Durkheim, o Estado é a sede de uma consciência especial e lúcida, as representações vindas dele são sempre mais claras e conscientes de suas causas e consequências. A consciência coletiva, por sua vez, é, em grande parte, difusa. Durkheim afirma que o individualismo só é possível através do Estado. Devido ao fato de possuir um tipo especial de consciência, por não se ater a particularidades e por estar afastado dos indivíduos, o Estado gera representações de um tipo especial, que envolvem a coletividade. Essas representações ordenam a vida coletiva e libertam o indivíduo dos grupos altruístas.

A ideia de um Estado que busca dar ordem aos interesses coletivos difusos é perceptível na política cultural do Estado Novo. A política cultural, nesse período, é marcada por um alto grau de intervencionismo estatal. Segundo Velloso, durante o Estado Novo

\footnotetext{
predomina a ideia de povo carente que necessita de condução firme e de vozes que possam falar por eles, exprimindo seus impulsos e anseios. A grosso modo, o raciocínio constrói-se da seguinte forma: o povo é potencialmente rico em virtudes - pureza, espontaneidade, autenticidade -, mas para manisfestar este seu aspecto positivo, precisa da intermediação das instâncias superiores. Estas tem o dom da expressão (intelectuais) e o da organização e da ordem (políticos). A imagem do estado "pai-grande" e a do intelectual salvacionista se entrecruzam, então, em direção ao popular (VELLoso, 1987, p. 48).
} 
Sérgio Miceli (2001) afirma que os intelectuais, durante o Estado novo, tenderam a ocupar os cargos que dispunham dos maiores vencimentos, se inserindo em espaços privilegiados do serviço público. Segundo Miceli, um seleto grupo de intelectuais ocupavam cargos da cúpula do poder executivo. Miceli aponta que os intelectuais tenderam a monopolizar cargos em que trabalhavam como administradores culturais. Muitos deles dirigiram instituições culturais, como o Museu Histórico Nacional, a Biblioteca Nacional, entre outros institutos culturais. Os intelectuais ocupavam também cargos nas instituições de difusão cultural, de propaganda e de censura.

Segundo Velloso, a ligação entre intelectuais e Estado fez surgir uma política cultural marcada por um projeto pedagógico. Intelectuais ligados a vanguarda do movimento modernista, como Carlos Drummond de Andrade, Lúcio Costa e Portinari, tiveram grande participação nesse projeto.

Frederico da Silva (2007) afirma que as normas jurídicas criadas até 2001, como a Lei Sarney, que foi a primeira lei de incentivo, a Lei Rouanet, e a medida provisória MP $\mathrm{n}^{\circ}$ 2.228, de setembro de 2001, que criou o Programa de Apoio ao Desenvolvimento do Cinema Nacional (Prodecine) e o Fundo de Financiamento da Indústria Cinematográfica (Funcine), formaram a base da estrutura do sistema de financiamento cultural público no Brasil. Segundo Da Silva, o financiamento público à cultura no Brasil ocorre de três modos: através dos recursos orçamentários, dos incentivos fiscais e dos fundos de investimento.

Fazem parte dos recursos orçamentários o montante destinado ao Fundo Nacional de Cultura (FNC) e os recursos provenientes das instituições federais. 0 valor destinado aos recursos orçamentários para a cultura a partir de 1995 não sofreu muitas variações. As quedas nos valores orçamentários coincidem com os anos em que houve períodos de crise econômica. Apesar de algumas flutuações no montante de recursos orçamentários entre 1995 e 2002, eles exerceram um papel importante no financiamento da cultura nesse período. A média da participação dos recursos orçamentários no total de recursos destinados ao financiamento cultural nesse período foi de $45,7 \%$.

Os fundos de investimento, como o Ficart e o Funcine, não foram, segundo Da Silva, muito efetivos até o momento atual, mas têm um grande potencial como fonte de recursos no futuro.

Por meio dos incentivos fiscais, as pessoas físicas e as empresas têm a opção de doar parcelas dos impostos pagos por elas para apoiar diretamente as atividades 
culturais. Uma parte dos recursos dos incentivos fiscais é proveniente do imposto que o Estado deixa de arrecadar e outra parte é uma parcela adicional de recursos dos próprios empresários. Os incentivos são o modo de arrecadação de recursos que possui maior participação no total de recursos, superando, entre 1995 e 2002, os valores arrecadados pelos recursos orçamentários. Os valores arrecadados pelos incentivos fiscais sofreram flutuações entre 1995 e 2002. Nesse período, houve uma diminuição gradual da participação adicional dos empresários.

\section{Considerações finais}

É possível observar enormes mudanças nos valores, na economia, na política e nas práticas culturais entre os períodos moderno e pós-moderno. No que diz respeito às práticas culturais, é importante observar que tanto o produtor quanto o produto cultural adquiriram novas funções a partir da transição da modernidade para a pós-modernidade.

O financiamento da cultura no Brasil sofreu diversas alterações nas últimas décadas. A partir de 1937, ocorreu uma aproximação entre o Estado, visto como um ordenador da coletividade, e a esfera cultural. Nesse período, o Estado passa a intervir fortemente na esfera cultural com o objetivo de conduzir as expressões culturais. Os intelectuais passam a atuar como legisladores, pois, em conjunto com o Estado, buscam ordenar os gostos e as práticas culturais com a finalidade de construir uma identidade nacional. Durante o Estado Novo, a política cultural é marcada por um forte intervencionismo, pela censura e pela preservação de algumas práticas consideradas pertencentes à cultura nacional. As características da política cultural do Estado Novo se mantêm, em maior ou menor grau, até o fim do governo militar.

Como afirma Inglehart, uma das características da pós-modernidade é a mudanças de valores. Enquanto a modernidade teria uma ênfase na disciplina coletiva, a pós-modernidade estaria ligada a uma busca por autonomia individual. A política cultural do Estado Novo, que contava com uma grande participação de intelectuais modernistas, tinha como ênfase o ordenamento coletivo. Por outro lado, a partir de 1988 a política cultural é marcada sobretudo por uma tentativa de democratização dos direitos culturais. 0 objetivo não é mais controlar ou ajustar as práticas culturais, mas sim incentivar produções culturais diversas e facilitar o consumo de cultura.

Enquanto na política cultural moderna existe uma diferenciação entre expressões culturais válidas e expressões culturais que precisam ser transformadas, na po- 
lítica cultural pós-moderna a diferenciação se dá entre consumidores. 0 consumo cultural na pós-modernidade funciona como indicador da individualidade do gosto e do senso de estilo do consumidor. Isaura Botelho (2001) afirma que estudos inovadores, como o estudo inaugural de Pierre Bourdieu sobre os museus (1969), tiveram grande influência nas políticas culturais em âmbito global. A partir desses estudos, foi possível perceber a existência de um público plural dividido em subpúblicos. A ideia de uma cultura erudita legítima que representaria os melhores valores da nação é abandonada. Emmanuel Négrier (2003) afirma que, a partir da década de 80, a política cultural francesa começou a trabalhar com um paradigma que reconhece formas de produção cultural legítimas, como a gastronomia, o rock e a moda. Essa mudança de paradigmas também ocorreu no Brasil, onde houve um abandono da política cultural do Estado Novo que elegia certas práticas como pertencentes à cultural nacional, substituindo-a por outra baseada no reconhecimento da legitimidade de diversas práticas.

A lei N 8.313 de 23 de Dezembro de 1991 trata da criação do programa nacional de apoio à cultura (PRONAC). A lei estabelece os fins perseguidos pelo PRONAC.

Art. $1^{\circ}$ Fica instituído o Programa Nacional de Apoio à Cultura (Pronac), com a finalidade de captar e canalizar recursos para o setor de modo a:

I - contribuir para facilitar, a todos, os meios para o livre acesso às fontes da cultura e o pleno exercício dos direitos culturais;

II - promover e estimular a regionalização da produção cultural e artística brasileira, com valorização de recursos humanos e conteúdos locais;

III - apoiar, valorizar e difundir o conjunto das manifestações culturais e seus respectivos criadores:

IV - proteger as expressões culturais dos grupos formadores da sociedade brasileira e responsáveis pelo pluralismo da cultura nacional;

$\mathrm{V}$ - salvaguardar a sobrevivência e o florescimento dos modos de criar, fazer e viver da sociedade brasileira;

VI - preservar os bens materiais e imateriais do patrimônio cultural e histórico brasileiro; VII - desenvolver a consciência internacional e o respeito aos valores culturais de outros povos ou nações;

VIII - estimular a produção e difusão de bens culturais de valor universal, formadores e informadores de conhecimento, cultura e memória;

IX - priorizar o produto cultural originário do País (BRASIL, 1991).

É possível perceber que os objetivos traçados pela lei 8.313 se aproximam bastante de alguns aspectos pós-modernos. Há uma maior atenção a pluralidade cultural e ao local, em detrimento do universal/nacional. Essas são características típicas do pós-modernismo. Além disso, é possível observar o surgimento de novos valores, como o respeito às diferenças culturais. Os fundos de cultura e leis de incentivo dão maior foco à criação plural de bens culturais do à preservação de certos bens específi- 
cos. 0 reconhecimento múltiplo da legitimidade de criação e difusão representa uma grande ruptura no próprio papel da produção, do produto e do consumo cultural. A maior parte do financiamento público da cultura se dá através das leis de incentivo, que fornecem instrumentos para a produção cultural. Elas buscam atender áreas culturais distintas, como a literatura, as artes plásticas, o circo e alguns setores da indústria cultural como o cinema.

\section{Referências}

BAUMAN, Z. (2010). Legisladores e intérpretes. Rio de Janeiro: Jorge Zahar. (1998). O mal-estar da pós-modernidade. Rio de Janeiro: Jorge Zahar.

BENJAMIN, W. (1985). "A obra de arte na era de sua reprodutibilidade técnica". In: Obras escolhidas: magia e técnica, arte e política. Vol. I. São Paulo: Brasiliense.

Botelho, I. (2001). "Dimensões da cultura e políticas públicas". São Paulo em Perspectiva, São Paulo, vol.15, n. 2.

Bourdieu, P. (2005). A economia das trocas simbólicas. São Paulo: Perspectiva. (1990). "Ponto de referência". In: Coisas ditas. São Paulo: Brasiliense.

BrASIL (1991). Lei n 8.313, de 23 de Dezembro de 1991.

Chauí, M. (1995). "Cultura política e política cultural". Estudo avançados, São Paulo, vol. 9 , n. 23.

DA SiLVA, F. A. B. (2007). Economia e política cultural: acesso, emprego e financiamento. Brasília: Ministério da Cultura.

DEJEAN, J. (2005). Antigos contra modernos. Rio de Janeiro: Civilização Brasileira.

Durkheim, E. (1983). Lições de Sociologia. São paulo: T. A. Queiroz.

Featherstone, M. (1995). Cultura de consumo e pós-modernismo. São Paulo: Studio Nobel.

Focault, M. (2009). A ordem do discurso. São Paulo: Loyola.

Giddens, A. (1991). As consequências da modernidade. São Paulo: Ed. UNESP.

HABERMAS, J. (1998). O discurso filosófico da modernidade. Lisboa: Dom Quixote. 
HARvey, D. (1993). Condição pós-moderna. São Paulo: Loyola.

Hutcheon, L. (1991). Poética do pós-modernismo: história, teoria, ficção. Rio de Janeiro: Imago.

INGLEHART, R. (2005). Modernização, mudança cultural e democracia: a sequência do desenvolvimento humano. São Paulo: Francis.

JAmeson, F. (1997). Pós-modernismo: a lógica cultural do capitalismo tardio. São Paulo: Ática.

NÉGRIER, E. (2003). Las políticas culturales en Francia y España. Barcelona: Institut de Ciències Polítiques i Socials.

MiCELI, S. (1985a). "As tradições do mecenato europeu nos campos das artes cênicas, da música e de rádio-televisão". In: MICELI, S; GOUVEIA, M. A. (Org.). Politica cultural comparada. Rio de Janeiro/São Paulo: FUNARTE/FINEP/IDESP.

(1985b). "O financiamento das artes nos EUA: filantropia privada versus patrocínio governamental". In: MICELI, S.; GOUVEIA, M. A. (Org.). Politica cultural comparada. Rio de Janeiro/São Paulo: FUNARTE/FINEP/IDESP.

(2001). Intelectuais à brasileira. São paulo: Companhia das Letras.

Velloso, M. P. (1987). Os intelectuais e a política cultural do Estado Novo. Rio de Janeiro: Centro de Pesquisa e Documentação de História Contemporânea do Brasil.

Venturi, R.; Scott-Brown, D. (1978). Learning from Las Vegas: the forgotten symbolism of architectural form. Cambridge: MIT Press.

Weber, M. (2003). A política como vocação. Brasília: Ed. UNB.

Williams, R. (1992). Cultura. São Paulo: Paz e Terra.

Recebido em maio/2012

Aprovado em setembro/2012 